\title{
Dependence of braking vehicle characteristics on environmental conditions
}

\author{
Krasnoshtanov Sergey Yurievich \\ Irkutsk National Research Technical University \\ Irkutsk, Russian Federation \\ $\underline{\text { sk@istu.edu }}$
}

\author{
Bykov Alexander Vladimirovich \\ East Siberia State University of Technologies and \\ Management \\ Ulan-Ude, Russian Federation \\ pkesstu@mail.ru
}

\author{
Tikhov-Tinnikov Dmitry Anatolyevich \\ East Siberia State University of Technologies and Management \\ Ulan-Ude, Russian Federation \\ $\underline{\mathrm{dm} \text { tt@mail.ru }}$
}

\begin{abstract}
The main purpose of the work is to confirm influence of operating conditions at low temperatures on change in braking characteristics of cars. The factors influencing the result of braking are determined, cars from the general set of all vehicles operated in Ulan-Ude are selected, taking into account certain conditions. A test method is proposed that makes it possible to obtain functional dependences of the specific braking force on ambient temperature during storage of the vehicle, and also the functional dependences of the specific braking force on storage temperature under operating conditions in Ulan-Ude are obtained. The insignificant influence of air humidity on results of the braking process in conditions of Ulan-Ude was revealed. The correlation of the value of specific braking force from the ambient temperature was estimated, the statistical indices obtained indicate a high correlation between the compared values. The tasks of further studies that need to be performed to determine most complete picture of the influence of ambient temperature and air humidity on parameters of the functioning of brake system a vehicle were determined.
\end{abstract}

Keywords - Motor vehicle, temperature, braking, natural and climatic conditions

\section{INTRODUCTION}

When preparing and planning experiments, it was suggested that under influence of external natural and climatic factors, namely ambient temperature and air humidity, the braking performance indicators ensuring safety of the vehicle operation may differ greatly from the values obtained during technical inspection of the vehicle.

Factors influencing the result of inhibition were determined:

- type and condition of the road surface;

- the presence and intensity of precipitation;

- the condition of the roadway and the presence of contaminants, rolled snow and ice on it;
- presence of malfunctions in brake system and a suspension bracket of the car;

- type and condition of car tires;

- design features of vehicles.

The main purpose of the work was to confirm influence of operating conditions at low temperatures on change in braking characteristics of vehicles. To do this, we selected cars with certain conditions from the general population of all vehicles operating:

- Cars as the most representative group (more than $79 \%$ of the total number of vehicles operated in UlanUde).

- Cars are least involved in commercial transport;

- Cars have the same type of brake drive (volumetric hydraulic).

- Cars have not a significant change in the actual mass during operation, unlike trucks and buses.

- Cars during the test ensure a more even distribution of mass along the axes.

- Cars have a narrower tire size with a large nomenclature.

The tests were carried out on cars equipped with different types of hydraulic brake drive and brake mechanisms, namely:

- with front disc and rear drum brakes without anti-lock braking system;

- with front disc and rear drum brakes with anti-lock braking system;

- with front and rear disc brakes with anti-lock braking system. 
To exclude or neutralize the factors that affect braking results, the tests were carried out using a test stand method on the STM $3500 \mathrm{~m}$ roller brake tester. With this approach, influence of the first three factors is excluded: road surface, precipitation, pollution and winter slipperiness. In order to ensure consistency of the technical condition of the vehicle's systems and components were allowed vehicles:

- with a serviceable suspension;

- with residual wear of the tires at least $50 \%$ of the initial value of the tread height without external damages;

- with properly inspected and having adjusted braking mechanisms.

\section{THE METHODOLOGY OF THE TESTS}

For planning tests, information was used on number of vehicles in operation in the Republic of Buryatia [1]. The data are shown in Table I:

TABLE I. NUMBER OF OPERATING MOTOR VEHICLES

\begin{tabular}{|l|c|c|c|}
\hline \multicolumn{1}{|c|}{ Year } & $\mathbf{2 0 1 3}$ & $\mathbf{2 0 1 4}$ & $\mathbf{2 0 1 5}$ \\
\hline Trucks only & 46459 & 51734 & 54069 \\
\hline of them owned by citizens & 33232 & 36430 & 38174 \\
\hline Buses only & 12553 & 13330 & 14167 \\
\hline of them owned by citizens & 9998 & 10435 & 11083 \\
\hline Cars only & 240904 & 252870 & 263967 \\
\hline of them owned by citizens & 225099 & 234078 & 238976 \\
\hline
\end{tabular}

During planning and carrying out tests, modified test stand technique described in GOST R 51709-2001 was used and regulatory requirements for the braking performance parameters given in Technical Regulations of the Customs Union 018/2011 [2, 3].

In accordance with requirements of the standards, during tests, brake force control was carried out, control relative difference in braking forces on wheels of one axle, calculation of the specific braking force of car's braking system. The test impact on brake pedal was set according to requirements of the procedure, and did not exceed 490 Newtons. The braking was carried out either before maximum force was reached on pedal, or before blocking of the wheels on brake calipers began. To ensure the test impact, it was very important to resolve issue of its organization, while time interval of exposure was set in range of 6-12 seconds. [4, 5, 6, 7, 8].

In order to control temperature of the brakes and tires, a "Testo 110" instrument with a surface probe of the contact type was used. Information on temperature and humidity of the ambient air was taken from meteorological station of UlanUde at time of the tests.

The region of Ulan-Ude carries out a large amount of annual amplitude of ambient temperature fluctuations is characterized by abnormally low temperatures with respect to conditions of a moderately cold climate. Average annual air temperatures are negative, a small amount of precipitation with uneven distribution throughout year, is also characterized by sharp diurnal temperature fluctuations. For the test area, January and February are the coldest months [9].

In order to determine parking time of the car, at which equilibrium temperature is reached with surrounding environment under open storage conditions, time intervals were measured at different temperature conditions. At the same time, to level influence of solar radiation and wind, parking was carried out in shadow of a continuous fence on leeward side.

In season of 2016-2017, graphs were obtained of bringing temperature of the test objects to an equilibrium state with ambient temperature and time intervals for settling car in an open parking lot during testing were determined. In addition, graphs describing change in magnitude of the specific braking force from ambient temperature [10]. The time intervals used for parking are shown in Table II.

TABLE II. THE TIME TO REACH EQUILIBRIUM TEMPERATURE WHEN TESTING

\begin{tabular}{|c|c|}
\hline The ambient air temperature, ${ }^{\circ} \mathbf{C}$ & Time interval at least \\
\hline$-14 \ldots 0$ inclusive & 180 \\
\hline$-24 \ldots-15$ inclusive & 120 \\
\hline$-40 \ldots-35$ inclusive & 90 \\
\hline
\end{tabular}

The parking time of the car before tests should ensure that equilibrium temperature is reached with environment and is recommended with a certain margin. A good agreement was found between curves of the temperature drop of the braking mechanisms and tires with the empirical Newton-Rihman cooling law [11]:

$$
d Q / d T=\alpha \times S \times\left(T_{s}-T\right)
$$

$Q$ is amount of heat;

$S$ is surface area of the body through which heat is transferred;

$T$ is body temperature;

$T_{s}$ is ambient temperature;

$\alpha$ is a coefficient of heat transfer, depending on geometry of the body, surface state, heat transfer regime and other factors. 


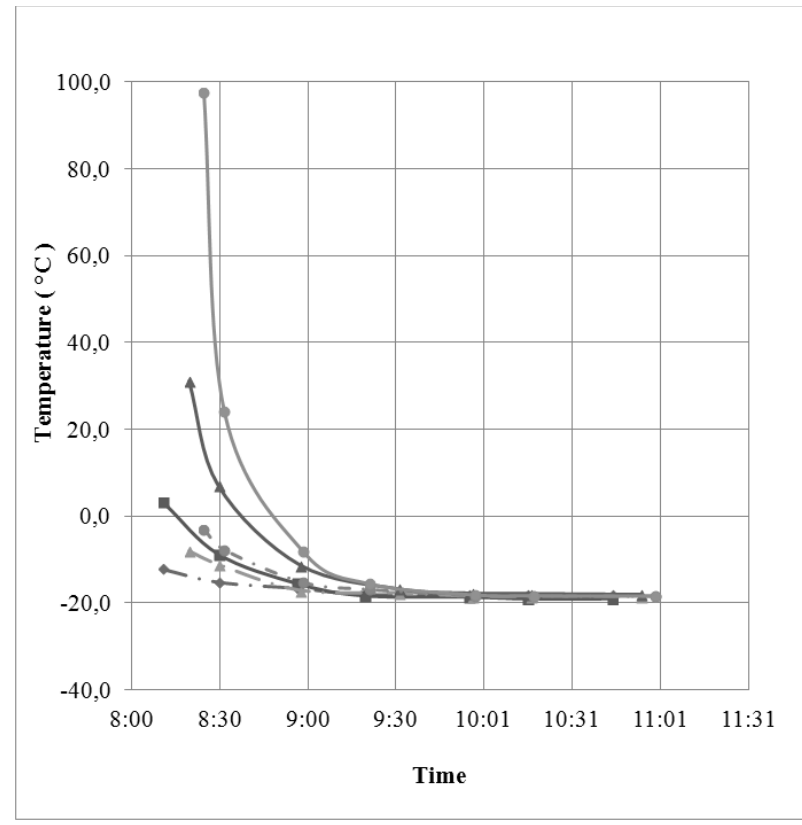

Fig. 1. Bringing temperature of the object to equilibrium

\section{RESULTS AND DISCUSSION}

During the tests in season 2016-2017, functional dependences of the specific braking force on storage temperature of vehicles for vehicles without anti-lock braking system and for cars with anti-lock braking system were obtained. and 3 .

The resulting dependency curves are shown in Figures 2

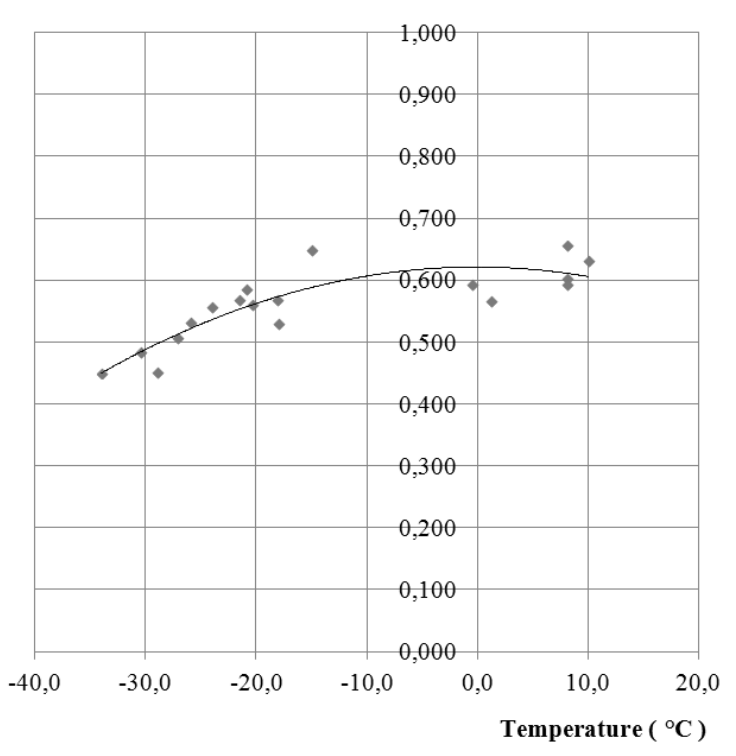

Fig. 2. The value of specific braking force for car Renault Sandero.

Obtained functional dependence of the specific braking force Renault Sandero car from ambient temperature during commencement of the movement:

$$
y=-0,0001 \times T^{2}-0,00003 \times T+0,621
$$

$y$ - specific brake force;

$T$ - temperature, ${ }^{\circ} \mathrm{C}$.

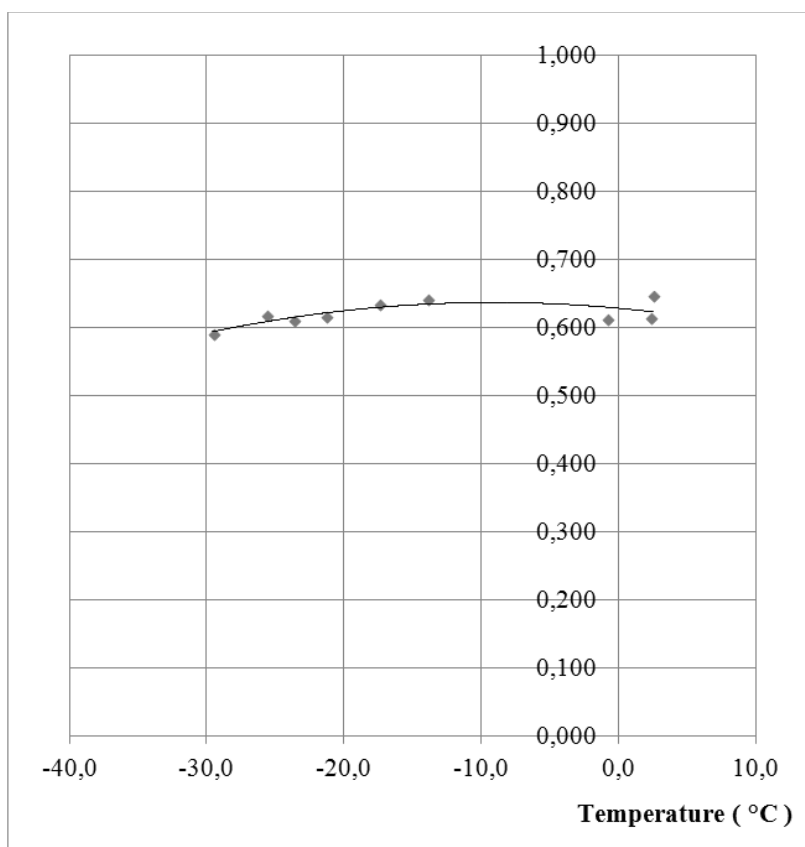

Fig. 3. The value of specific braking force for car Ford Mondeo.

Obtained functional dependence of the specific braking force Ford Mondeo car from ambient temperature during commencement of the movement:

$$
y=-0,0001 \times T^{2}-0,0025 \times T+0,837
$$

Renault Sandero car, which does not have an anti-lock braking system, showed a greater drop in braking performance compared to Ford Mondeo car, while braking performance was still within acceptable range. However, taking into account winter slipperiness on roads during operation, this reduction can negatively affect road safety and provoke a traffic accident.

Ford Mondeo car, equipped with a more modern braking system with anti-lock block, showed a much smaller reduction in braking performance. In this case, it is necessary to take into account that it was not possible to check the efficiency of braking when parking below $-35^{\circ} \mathrm{C}$ to $-50^{\circ} \mathrm{C}$ during investigations in the region of Ulan-Ude.

Obtained statistical characteristics showed a satisfactory description of the relationship between magnitude of the specific braking force and storage temperature. Calculated correlation index, determination index and Fisher's criterion were for cars without the anti-lock braking system: $R=0.863$, $R^{2}=0.745, F=21.95$, for cars with the anti-lock braking system respectively: $R=0.808, R^{2}=0.653, F=5.64$.

In the 2017-2018 season, repeated tests were carried out and similar equations were obtained for vehicles without an 
anti-lock system (Fig. 4) and equipped with the anti-lock braking system (Fig. 5, 6).

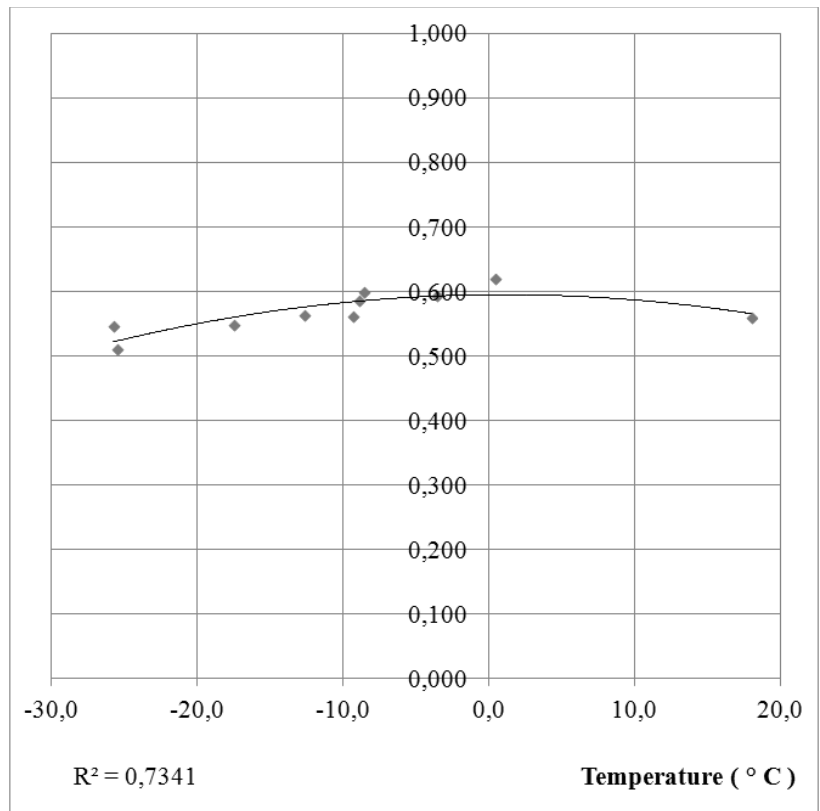

Fig. 4. The value of specific braking force for car Toyota Camry

Obtained functional dependence of the specific braking force of Toyota Camry car from ambient temperature during commencement of the movement:

$$
y=-0,0001 \times T^{2}+0,0002 \times T+0,5946
$$

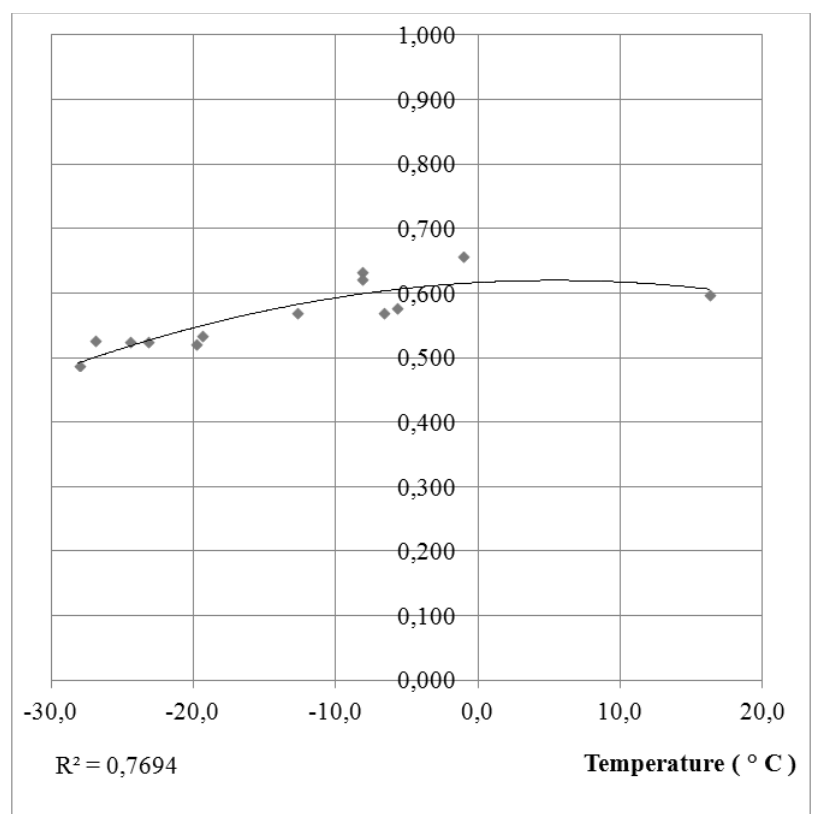

Fig. 5. The value of specific braking force for car Toyota Corolla

Obtained functional dependence of the specific braking force of Toyota Corolla car from ambient temperature during commencement of the movement:

$$
y=-0,0001 \times T^{2}+0,0012 \times T+0,6163
$$

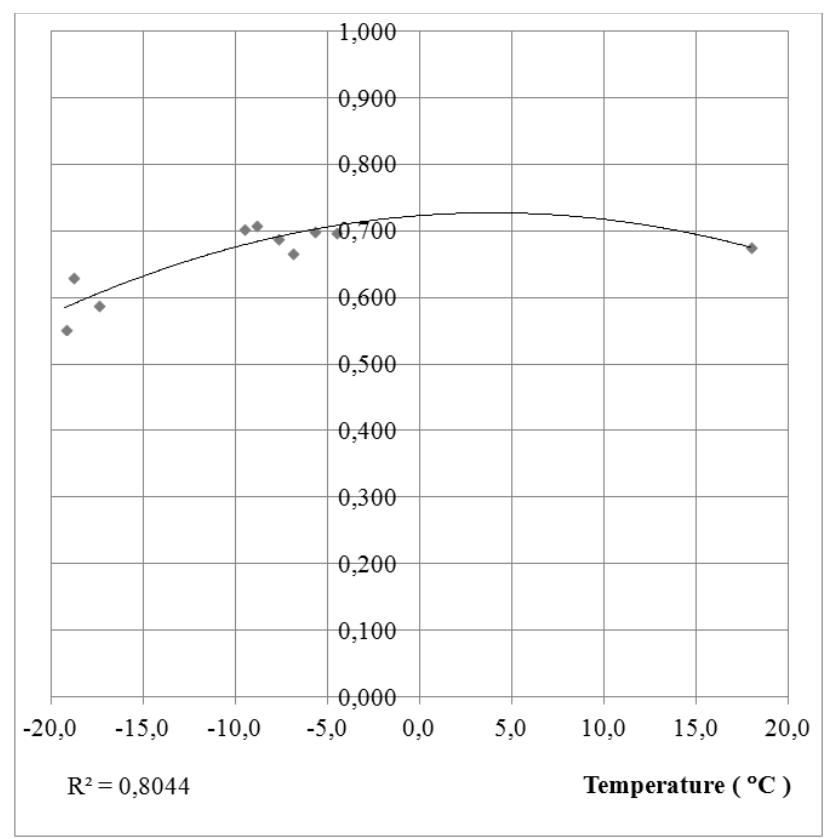

Fig. 6. The value of specific braking force for car Honda Edix

Obtained functional dependence of the specific braking force of Honda Edix car from ambient temperature during commencement of the movement:

$$
y=-0,0003 \times T^{2}+0,0021 \times T+0,7227
$$

When testing one of the selected cars, namely Toyota Camry also in the basic configuration did not have an antilock braking system. All other tested vehicles were equipped with anti-lock braking systems. The systems used differed in production date and operating algorithms.

Testing of the braking efficiency of Toyota Camry and Toyota Corolla vehicles showed very close characteristics for these models, while braking performance was within permissible range and had some reserve.

Honda Edix car, equipped with a more modern braking system with anti-lock block, showed higher specific braking force in the temperature range under consideration, but a greater decrease in braking efficiency at significant negative operating temperatures, compared to the obtained values of the specific braking force in the zero temperature zone.

At this stage, it was also not possible to check the braking efficiency when parking below $-30^{\circ} \mathrm{C}$ during investigations in vicinity of Ulan-Ude. Obviously, to assess efficiency of inhibition at lower temperatures, it is necessary to change the region of observations.

To assess correlation dependence, we used a standard mathematical apparatus implemented in Excel MS Office package and obtained polynomials of the second degree describing change in value of the specific braking force from ambient temperature. 
Obtained correlations indices show high closeness of the connection between value of the specific braking force and storage temperature. Calculated indices of the determination $R^{2}$, which characterize the share of the variance of the resultant attribute explained by the regression, are shown in Fig. 4-6. Results of the evaluation of functional dependencies are presented in Table III.

TABLE III. EVALUATION STATISTICS

\begin{tabular}{|c|c|c|c|}
\hline \multirow{2}{*}{ Statistical characteristic } & \multicolumn{3}{|c|}{ Car model } \\
\cline { 2 - 4 } & $\begin{array}{c}\text { Toyota } \\
\text { Camry }\end{array}$ & $\begin{array}{c}\text { Toyota } \\
\text { Corolla }\end{array}$ & $\begin{array}{c}\text { Honda } \\
\text { Edix }\end{array}$ \\
\hline Correlation index, R & 0.85 & 0.88 & 0.89 \\
\hline $\begin{array}{c}\text { Average error of approximation, } \\
\bar{A}(\%)\end{array}$ & 2.38 & 4.82 & 3.14 \\
\hline Coefficient of elasticity, E & -0.05 & -0.12 & -0.11 \\
\hline Determination index, R ${ }^{2}$ & 0.74 & 0.77 & 0.80 \\
\hline Fisher's calculated test, F & 9.91 & 16.9 & 14.39 \\
\hline
\end{tabular}

Based on studies carried out, further research tasks have been determined. It is necessary to determine nature of the dependence of the specific braking force (or braking forces) on ambient temperature during period of steady motion, under influence of negative temperatures.

In this case, it is necessary to detect influence of the ambient temperature on operation of the elements of the brake system, in particular brake drive and executive brake mechanisms. In addition, it is necessary to identify effect of anti-lock braking systems on efficiency of the braking process at significant negative ambient temperatures, and also to determine level of influence of the ambient temperature on the performance of braking through state of the suspension and chassis

The given research problems should be solved with use of mathematical modeling of braking processes of cars taking into account influence of environmental parameters, namely temperature and humidity of air.

Mathematical modeling, is, to date, one of the main components of scientific and technological progress, since technical systems of the car and object of research itself are a motor vehicle, are no longer subject to research in required completeness and accuracy by conventional theoretical methods. At same time, a direct full-scale experiment is often very long, expensive and difficult to realize or impossible to implement.

The developed mathematical models of the brake drive, braking mechanism and car as a whole should be investigated by theoretical methods, which will allow obtaining important preliminary knowledge about object, and it is necessary to use some assumptions that simplify understanding of the braking process. It is necessary to identify all factors and effects that will be irrelevant in describing process, and to exclude them. If possible, idealizing assumptions must be written in mathematical form, so that their justice can be quantified.

The next step is formulation or choice of the law to which object is subject and its record in mathematical form. If necessary, additional information about object should also be formalized in mathematical form if possible. Received model of process of braking of the vehicle should be supplemented with initial values of the parameters considered at modeling, limiting conditions, constant sizes, without knowledge of which it is impossible to define behavior of the vehicle.

Obtained mathematical description, realized in model of the braking process of a car, taking into account influence of external factors, namely temperature of the ambient air and humidity of the air, will enable us to understand patterns of change in state of the object of investigation.

\section{CONCLUSION}

When carrying out procedure for technical control of the condition of vehicles, requirements to braking performance indicators prescribed in Technical Regulations of the Customs Union 018/2011 "On the safety of wheeled vehicles" (Appendix No. 8) are used.

Fulfillment of these requirements makes it possible to provide necessary braking efficiency; however, technology of carrying out control tests does not take into account, in our opinion, inevitable change in parameters of the functioning of vehicle transport systems in real operating conditions. The efficiency indicators are checked, as a rule, in stationary conditions with standardized requirements to environment.

However, studies show that efficiency of vehicle braking changes with prolonged storage in an open parking environment at negative ambient temperatures. At least during commencement of the movement, braking efficiency of the serviceable brake system decreases, and with a decrease in storage temperature, drop in efficiency of the braking system is nonlinear and can be described by quadratic equations with acceptable accuracy.

On basis of conducted scientific researches, it is possible to make following conclusions:

- Obtained results confirm initial assumption about functional dependence of the braking performance (magnitude of the specific braking force) on operating conditions (temperature), at least during commencement of the movement.

- - Observed seasonal temperatures for period from 2016 to 2018 in Ulan-Ude and its environs do not allow to enter required statistics to clarify nature of the dependence of the specific braking force on ambient temperature in temperature range from $-35^{\circ} \mathrm{C}$ to $-50^{\circ}$ $\mathrm{C}$ in period of the beginning of the movement.

- Observed air humidity during the period of experiments in 2016-2018 did not have a significant effect on results. This statement is applicable only for conditions of operation in Ulan-Ude and its environs.

\section{References}

[1] Statistical Yearbook. Ulan-Ude: Buryatstat, 2016.

[2] GOST R 51709-2001. Vehicles. Safety requirements to technical conditions and test methods. Official edition. Moscow: Standartinform, 2008 . 
[3] Technical regulations of the Customs Union 018/2011. On safety of wheeled vehicles. Approved by Decision of the Commission Customs Union of December 9, 2011 No. 877.

[4] A.I. Fedotov, E.M. Portnyagin, "To the question about test actions to the object diag-investment”, Vestnik IrSTU,. vol. 5 (52), pp. 95-100, 2011.

[5] E.M. Portnyagin, Method of monitoring braking efficiency and stability of the vehicles with ABS when the diagnosis on roller stands: dis. candidate of technical sciences: the work is protected 02.07.2009. Orenburg: Orenburg GU, 2009.

[6] A.I. Fedotov, A.V. Boyko, A.S. Potapov, "On the repeatability of measurements of the parameters of the braking process of a car on a stand with running drums", Vestnik IrSTU, vol. 1 (33), pp. 63-71, 2008.

[7] A.V. Bojko, , A.I. Fedotov, W.P. Khalezov, M. Młyńczak, "Analysis of brake testing methods in vehicle safety", Safety and Reliability:
Methodology and Applications, pp. 933-937, September 2014, [Proceedings of the European Safety and Reliability Conference (ESREL 2014), 2015].

[8] A.I. Fedotov, M. Młyńczak, "Simulation and experimental analysis of quality control of vehicle brake systems using flat plate tester", Advances in Intelligent Systems and Computing, vol 470, pp. 135-146, 2016.

[9] Scientific-applied Handbook on the USSR climate. Edition 23. Buryat ASSR. Chita area. Leningrad: Gidrometeoizdat, 1989.

[10] V.G. Zedgenizov, A.V. Bykov, "Assessment of motor vehicle braking performance dependence on ambient temperature", Proceedings of Irkutsk State Technical University, vol. 21 (131), pp. 220-225, 2017.

[11] G. Rihman, Writings on physics. Moscow: AS USSR, 1956. 